\title{
AST-120 (SPHERICAL CARBON ADSORBENT) LOWERS AMMONIA LEVELS AND ATTENUATES BRAIN EDEMA IN BILE DUCT-LIGATED RATS
}

\section{Cristina R. Bosoi, Christian Parent-Robitaille, Keith Anderson, Mélanie Tremblay and Christopher F. Rose}

1. Neuroscience Research Unit, Hôpital Saint-Luc (CRCHUM), Université de Montréal, Québec, Canada

2. Ocera Therapeutics, San Diego, CA

${ }^{\dagger}$ Supported by Ocera Therapeutics, San Diego, CA. "Potential conflict of interest: Nothing to report.

\section{ABSTRACT}

The pathogenesis of hepatic encephalopathy is multifactorial, involving gut-derived toxins such as ammonia, which has been demonstrated to induce oxidative stress. Therefore, a primary hepatic encephalopathy treatment target is reducing ammonia production in the gastrointestinal tract. AST-120, an oral adsorbent of engineered activated carbon microspheres with surface areas exceeding $1600 \mathrm{~m}^{2} / \mathrm{g}$, acts as a sink for neurotoxins and hepatotoxins present in the gut. We evaluated the capacity of AST-120 to adsorb ammonia in vitro and to lower blood ammonia, oxidative stress and brain edema in cirrhotic rats. Cirrhosis was induced in rats by bile duct ligation for 6 weeks. AST-120 was administered by gavage preventively for 6 weeks $(0.1,1$, and $4 \mathrm{~g} / \mathrm{kg} / \mathrm{day})$. In addition, AST-120 was evaluated as a short-term treatment for 2 weeks and 3 days $(1 \mathrm{~g} / \mathrm{kg} / \mathrm{day})$ and as a sink to adsorb intravenously infused ammonium acetate. In vitro, AST-120 efficiently adsorbed ammonia. Ammonia levels significantly decreased in a dose-dependent manner for all AST-120-treated bile duct-ligated rats (nontreated: $177.3 \pm 30.8 \mu \mathrm{M}$; AST-120, $0.1 \mathrm{~g} / \mathrm{kg} / \mathrm{day}: 121.9 \pm 13.8 \mu \mathrm{M}$; AST-120, $1 \mathrm{~g} / \mathrm{kg} / \mathrm{day}: 80.9 \pm 30.0 \mu \mathrm{M}$; AST-120, $4 \mathrm{~g} / \mathrm{kg} /$ day: $48.8 \pm 19.6 \mu \mathrm{M})$ and significantly correlated with doses of AST-120 $(r=-0.6603)$. Brain water content and locomotor activity normalized after AST-120 treatments, whereas arterial reactive oxygen species levels remained unchanged. Furthermore, AST-120 significantly attenuated a rise in arterial ammonia after ammonium acetate administration (intravenously). Conclusion:AST-120 treatment decreased arterial ammonia levels, normalized brain water content and locomotor activity but did not demonstrate an effect on systemic oxidative stress. Also, AST-120 acts as an ammonia sink, efficiently removing blood-derived ammonia. Additional studies are warranted to evaluate the effects of AST-120 on hepatic encephalopathy in patients with advanced liver disease. (HEPATOLOGY 2011;)

\section{Abbreviations}

BDL, bile duct ligation; HE, hepatic encephalopathy; ROS, reactive oxygen species; SEM, standard error of the mean.

\section{INTRODUCTION}

Hepatic encephalopathy (HE) is a neuropsychiatric metabolic syndrome, a major complication of both acute and chronic liver disease. It is characterized by cognitive, psychiatric, and motor dysfunctions and can rapidly progress to hepatic coma and death. The prevalence of hepatic diseases is estimated at 5.5 million cases in 
United States, and as many as $80 \%$ of these patients develop minimal HE. ${ }^{1}$ The pathogenesis of HE is multifactorial, involving gut-derived toxins, the most important being ammonia. During liver failure, gut-derived ammonia is not metabolized by the liver, leading to hyperammonemia and consequently to toxic ammonia levels in the brain. ${ }^{2,3}$ Ammonia neurotoxicity has been associated with a number of pathophysiological, biochemical, and molecular changes in the brain, which consequentially lead to cerebral dysfunction. ${ }^{4}$ One important pathological change related to ammonia is represented by astrocyte swelling, which leads to brain edema. ${ }^{5}$ Brain edema, a common finding in patients with acute liver failure, ${ }^{6}$ is also observed in patients with cirrhosis, ${ }^{7-9}$ as well as in animal models of chronic liver failure. ${ }^{10}$

The correlation between ammonia and severity of HE in chronic liver failure remains controversial, ${ }^{11-14}$ and other factors are believed to act synergistically with ammonia to induce brain edema. ${ }^{15}$ Recently acute, high ammonia concentrations have been demonstrated to induce oxidative stress both in vitro ${ }^{16}$ and in vivo, ${ }^{17}$ suggesting an important role for oxidative stress in the pathogenesis of HE. ${ }^{18}$ Oxidative stress occurs during cirrhosis and represents a systemic phenomenon ${ }^{19}$; however, its relationship to HE or brain edema is unresolved. Reactive oxygen species (ROS) are believed to be produced at the intestinal level in relation to bacterial translocation and increased intestinal permeability, ${ }^{20}$ but also in the liver in relation to gut-derived toxins. ${ }^{21}$ Reactive oxygen species are known to be involved in blood-brain barrier dysfunction, ${ }^{22}$ which could enhance the neuropathological effects of ammonia. One of these effects could be brain edema, since in vitro, astrocyte swelling is related to ammonia-induced oxidative stress. ${ }^{23}$

Reducing ammonia levels remains a primary treatment strategy in patients with HE, and gut-derived ammonia represents an obvious treatment target. AST-120 consists of engineered activated carbon microspheres (0.2-0.4 $\mathrm{mm}$ in diameter) with high nonspecific adsorptive surface area $\left(>1600 \mathrm{~m}^{2} / \mathrm{g}\right)$. It is not adsorbed or degraded in the gastrointestinal tract and provides sustained binding surface for low-molecular-weight compounds $(<10 \mathrm{kDa})$ present in the bowel. ${ }^{24}$ AST-120 has proved to lower plasma ammonia levels in portacaval-shunted dogs ${ }^{25}$ and attenuate oxidative stress in uremic rats. ${ }^{26}$ Also, preliminary studies in humans have shown neurocognitive improvements in patients with low-grade HE after AST-120 treatment. ${ }^{27}$

The aim of this study was to evaluate the capacity of AST-120 to lower arterial ammonia (gut- and bloodderived) and oxidative stress and to investigate its effect on brain edema and locomotor activity in rats with cirrhosis induced by bile-duct ligation.

\section{MATERIALS AND METHODS}

\section{In Vitro Adsorption of Ammonia by AST-120.}

To determine the in vitro capacity of AST-120 to adsorb ammonia, $50 \mathrm{~mL}$ of 2 different ammonium chloride solutions $(100 \mu \mathrm{M}$ and $1 \mathrm{mM}, \mathrm{pH}=5.5)$ was incubated at room temperature with $2 \mathrm{~g}$ AST-120 for 1,3 , and 6

hours. Ammonia chloride solutions were incubated without AST-120 as controls. Samples were collected at each time point, and ammonia concentration was measured. Results were expressed as percentage of ammonia recovered in the solution after AST-120 adsorption.

\section{Animal Model.}

Secondary biliary cirrhosis was induced in male Sprague-Dawley rats (250 g) (Charles River, St. Constant, QC) after 6 weeks of bile duct ligation (BDL). Before the double ligation and resection, formalin $(1 \mu \mathrm{L} / \mathrm{mg}$ ) was injected intracholedochally to prevent the dilation of the ligated bile ducts. ${ }^{28}$ Control rats underwent a sham operation in which the bile duct was isolated without formalin injection, ligation, or resection. 


\section{AST-120 treatment.}

AST-120 (Ocera Therapeutics, San Diego, CA) was administered by gavage every 12 hours, for a period of 6 weeks, beginning day 1 after surgery. Sham and BDL rats $(n=6 /$ group $)$ received AST-120 dissolved in methylcellulose (Sigma, St. Louis, MO) (10 mL/kg/gavage) at a dose of 0.1, 1, and $4 \mathrm{~g} / \mathrm{kg} / \mathrm{day}$. Control sham and $\mathrm{BDL}$ rats $(n=6$ /group) received equivalent volumes of methylcellulose. Animals were sacrificed after 6 weeks. In the second part of the study, the effect of AST-120 administered as short-term treatment was evaluated. AST120 ( $1 \mathrm{~g} / \mathrm{kg} /$ day) was administered for 2 weeks (starting 4 weeks after surgery) and 3 days (starting day 39 after surgery) in both sham-operated and BDL rats.

To determine the capacity of AST-120 to adsorb ammonia from the periphery (blood), nontreated and AST-120treated BDL rats $(1 \mathrm{~g} / \mathrm{kg} /$ day for 2 weeks) were infused intravenously with ammonium acetate $(55$ $\mu \mathrm{mol} / \mathrm{kg} / \mathrm{minute}$ ) for 3 hours. ${ }^{29}$ Under isoflurane anesthesia, $22 \mathrm{G}$ catheters (Smiths Medical, United Kingdom) were placed in the aorta and vena cava and connected by PE60 tubing (Solomon Scientific, Plymouth Meeting, PA) to an infusion pump (CMA 100, Sweden). Rats were allowed to recover 30 minutes before starting the venous infusions. Aortic blood samples were collected at baseline and hourly to assess ammonia levels. Rats were sacrificed after 3 hours or at precoma stage (loss of righting reflex), if this occurred before 3 hours. All experiments were conducted following the Guidelines of Canadian Council on Animal Care and were approved by the Animal Protection Committee of CHUM Research Center.

Daily food/protein intake was monitored in BDL and sham-operated rats both untreated and treated with AST$120(1 \mathrm{~g} / \mathrm{kg} / \mathrm{day})$ for 2 weeks: 1 week before starting the treatment, and during the 2 weeks' treatment. Mean daily food/protein intake/100 g body weight was calculated and expressed as a percentage compared with nontreated sham-operated controls.

\section{Plasma Liver Function Markers.}

Plasmatic aspartate and alanine aminotransferase, bilirubin, alkaline phosphatase (AP), $\gamma$-glutamyl transpeptidase and albumin were measured using routine biochemistry techniques. Liver pathology was assessed as described in the supporting information.

\section{Ammonia.}

Ammonia levels were measured in arterial plasma using a commercial kit (Sigma, St. Louis, MO). Ammonia levels were assessed based on the reaction with $\alpha$-ketoglutarate and reduced nicotinamide adenine dinucleotide phosphate in the presence of L-glutamate dehydrogenase. Oxidation rate of reduced nicotinamide adenine dinucleotide phosphate was recorded by the absorbance decrease at $340 \mathrm{~nm}$. Ammonia concentration was calculated according to the manufacturer's protocol.

\section{ROS.}

Reactive oxygen species were assessed using the oxidation reaction of dichlorofluorescein diacetate (Invitrogen, Carlsbad, CA) to dichlorofluorescein. ${ }^{30}$ One hundred micromolar dichlorofluorescein diacetate was incubated for 30 minutes in dark with hydroxylamine hydrochloride $(40 \mathrm{mM})$ and hydrolyzed to nonfluorescent dichlorofluorescein. Dichlorofluorescein was incubated with arterial plasma, and the oxidation rate was recorded by changes in fluorescence over a 10-minute period with a spectrofluorometer (BioTek, Winooski, VT) at 485 $\mathrm{nm}$ excitation and $520 \mathrm{~nm}$ emission wavelengths.

\section{Brain Water Content.}

Brain water content was measured using the sensitive densitometry technique, as previously described. ${ }^{31}$ Briefly, after the animal was sacrificed, the frontal cortex was freshly dissected at $4^{\circ} \mathrm{C}$ and cut into $2-\mathrm{mm}^{3}$ pieces. Tissue pieces were placed in density gradient columns, and the equilibrium point was recorded after 2 minutes.

Columns were made with different kerosene and bromobenzene mixtures and precalibrated with $\mathrm{K}_{2} \mathrm{SO}_{4}$ solutions 
of known densities. Eight sample measurements were averaged in each rat. Water content was calculated based on tissue density, according to the formula described by Marmarou et al. ${ }^{31}$

\section{Locomotor Activity.}

Locomotor activity was assessed using an infrared beam computerized auto-track system (Columbus Instruments, Columbus, OH). ${ }^{32}$ Sham-operated controls, nontreated BDL, and BDL treated with AST-120 (1 $\mathrm{g} / \mathrm{kg} /$ day for 2 weeks) were individually placed in plexiglas cages $(29 \times 22 \times 22 \mathrm{~cm})$ for 6 hours before beginning to record activity. Cumulative distance traveled during the night (active) and day (inactive) period was recorded for $24 \mathrm{~h}$ and expressed as night/day ratio.

\section{Statistical Analysis.}

Data are expressed as mean \pm standard error of the mean (SEM). Significance of difference was tested with Student $t$ test and analysis of variance, followed by Newman-Keuls post-test; correlation was calculated with Spearman test using GraphPad Prism 4 (La Jolla, CA). Probability values $P<0.05$ were considered statistically significant.

\section{RESULTS}

\section{In Vitro Adsorption of Ammonia by AST-120.}

AST-120 significantly adsorbed ammonia at a $\mathrm{pH}$ similar to the physiological $\mathrm{pH}$ of the human gastrointestinal tract.33 The adsorption of ammonia by AST-120 is rapid, approximately $60 \%$ occurring during the first incubation hour, for both $100 \mu \mathrm{M}$ and $1 \mathrm{mM}$ solutions. After 6 hours of incubation, $2 \mathrm{~g}$ AST-120 removed 93.5\% $(93.5 \mu \mathrm{M})$ and $77.2 \%(772.3 \mu \mathrm{M})$ of $100 \mu \mathrm{M}$ and $1 \mathrm{mM}$ ammonia solutions, respectively (Fig. 1).

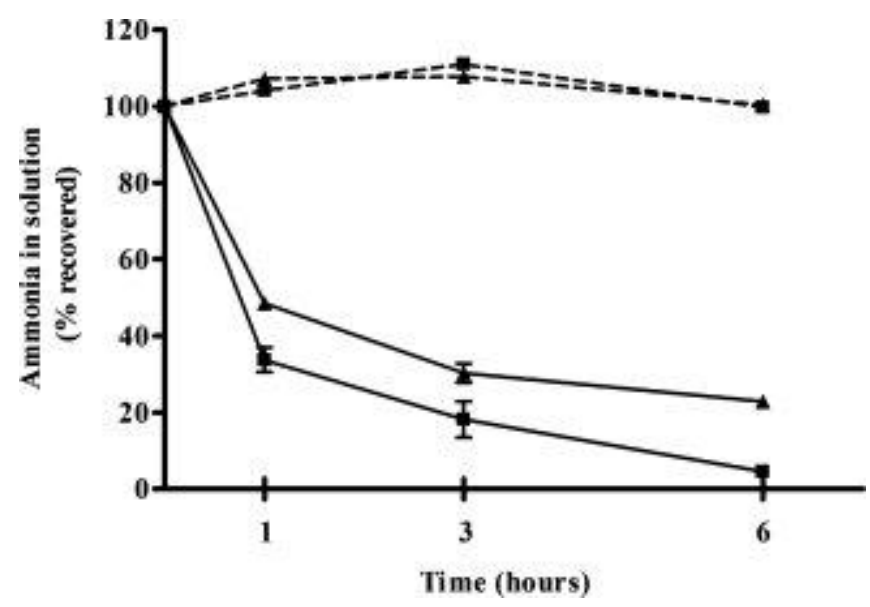

Figure 1. Ammonia recovered $(\%)$ in a volume of $50 \mathrm{~mL}$ of 2 different ammonium chloride solutions $(100 \mu \mathrm{M}$ and $1 \mathrm{mM})$ after 1,3 , and 6 hours of incubation in vitro with $2 \mathrm{~g}$ AST-120 (- - = ammonium chloride $[100 \mu \mathrm{M}]+$ AST-120; - - — = ammonium chloride $[1 \mathrm{mM}]+$ AST-120; --- - = ammonium chloride $[100 \mu \mathrm{M}]$; - - - - - = ammonium chloride $[1 \mathrm{mM}]$ ). 


\section{In Vivo Effect of AST-120 on Body Weight and Protein Intake.}

Bile duct-ligated rats gained significantly less weight than their respective sham-operated controls during the 6week course of the model. No significant difference was found between all four groups of sham-operated rats or between all four groups of BDL rats (nontreated and AST-120 treated) (Fig. 2A). Because no significant differences were found between the three groups of AST-120-treated sham-operated rats, the data were pooled and presented as mean values to simplify the figures.
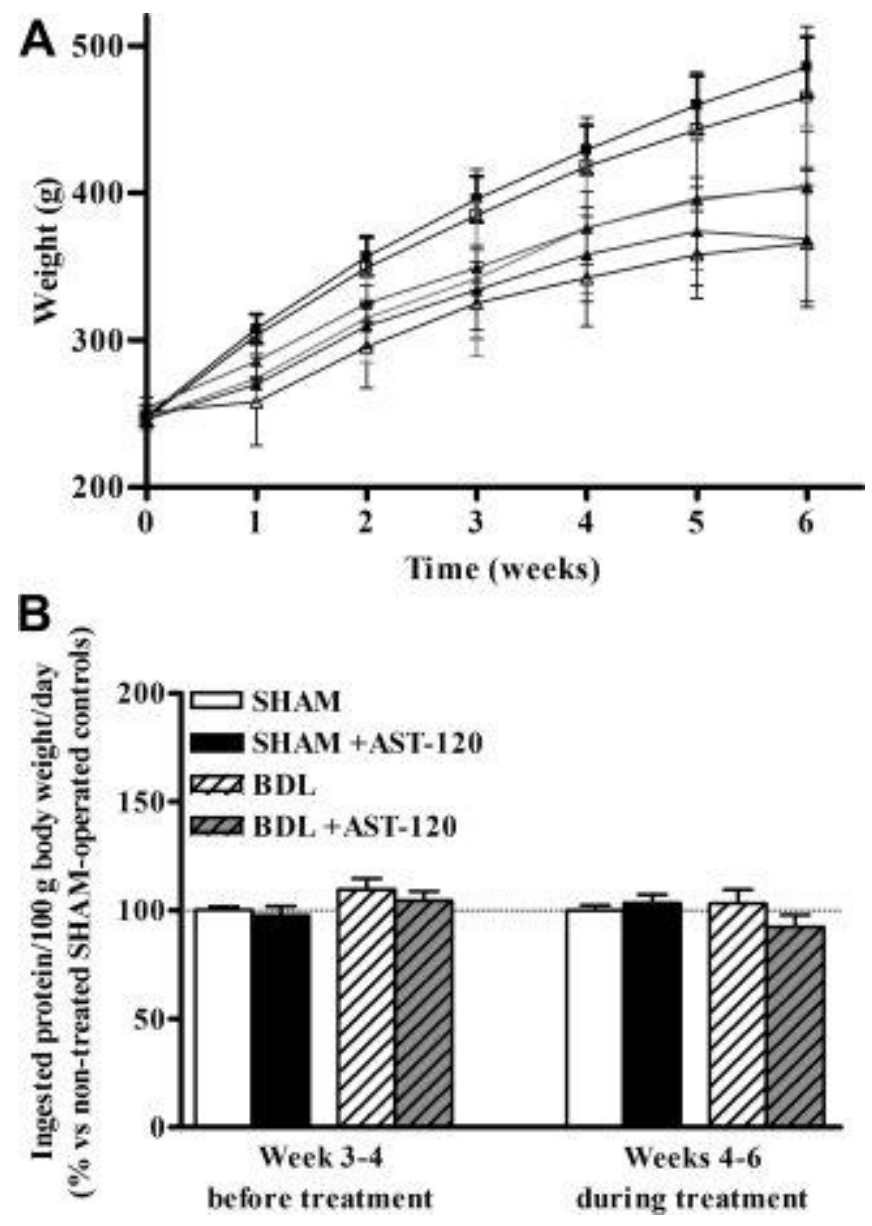

Figure 2. (A) Weight curves of bile-duct-ligated (BDL) and sham-operated rats under treatment with AST-120 0.1, 1, and $4 \mathrm{~g} / \mathrm{kg} /$ day for 6 weeks. Because no significant differences were found between the three groups of AST-120-treated sham-operated rats, only the mean value for these groups is presented to simplify the figure $(\square=\operatorname{sham;} \cdot=$ treated sham; $\Delta=$ nontreated BDL; $\Delta=$ AST-120, $0.1 \mathrm{~g} / \mathrm{kg} /$ day treated BDL; $\Delta=$ AST-120, $1 \mathrm{~g} / \mathrm{kg} /$ day treated BDL; $\Delta=$ AST-120, 4 $\mathrm{g} / \mathrm{kg} /$ day treated BDL). (B) Daily protein intake/100 g body weight in bile duct-ligated (BDL) and sham-operated rats under treatment with AST-120 $1 \mathrm{~g} / \mathrm{kg} /$ day for 2 weeks (starting 4 weeks after surgery). Data are expressed as percent change relative to sham-operated controls 1 week before starting the treatment (week 3-4) and during the treatment period (weeks 4-6).

The amount of protein ingested was not significantly different between BDL and sham-operated rats before starting the treatment, and neither group was affected by AST-120 (Fig. 2B). 


\section{Liver Biochemistry.}

At time of sacrifice, all BDL rats (nontreated and AST-120 treated) presented clinical signs of cirrhosis: jaundice, ascites, and enlarged, nodular, discolored liver. Levels of plasma aspartate aminotransferase, alanine aminotransferase, bilirubin, alkaline phosphatase, and gamma-glutamyltransferase were significantly increased in BDL groups compared with their corresponding sham-operated controls. In addition, albumin levels were significantly lower in all BDL rats compared with sham-operated controls (Table 1). Histopathological examination of liver sections revealed enlarged portal spaces with cholangiolar proliferation and hepatic necrosis in all BDL groups (Supporting Fig. 1). AST-120 treatment did not significantly improve liver function markers or histopathological changes.

Table 1. Liver Biochemistry Markers in Bile-Duct Ligated and Sham-Operated Rats Under Treatment With AST-120 at $0.1,1$, and $4 \mathrm{~g} / \mathrm{kg} /$ day for 6 Weeks

\begin{tabular}{ccccccc}
\hline & $\begin{array}{c}\text { AST } \\
(\mathrm{U} / \mathrm{l})\end{array}$ & $\begin{array}{c}\text { ALT } \\
(\mathrm{U} / \mathrm{l})\end{array}$ & $\begin{array}{c}\text { Bilirubin } \\
(\mu \mathrm{mol} / \mathrm{dl})\end{array}$ & $\begin{array}{c}\text { AP } \\
(\mathrm{U} / \mathrm{l})\end{array}$ & $\begin{array}{c}\text { GGT } \\
(\mathrm{U} / \mathrm{l})\end{array}$ & $\begin{array}{c}\text { Albumin } \\
(\mathrm{g} / \mathrm{l})\end{array}$ \\
\hline SHAM & $72 \pm 5$ & $46 \pm 3$ & $6.8 \pm 1.0$ & $196 \pm 12$ & $2.1 \pm 0.7$ & $20.2 \pm 0.5$ \\
treated SHAM & $67 \pm 3$ & $48 \pm 2$ & $6.0 \pm 0.4$ & $251 \pm 16$ & $3.2 \pm 0.4$ & $20.4 \pm 0.2$ \\
BDL & $401 \pm 35^{* * * *}$ & $125 \pm 30^{* * *}$ & $148.0 \pm 13.7^{* * *}$ & $520 \pm 65^{* * *}$ & $47.3 \pm 8.2^{* * *}$ & $<10^{* * *}$ \\
BDL 0.1 g/kg/day & $417 \pm 39^{\dagger \dagger \dagger}$ & $135 \pm 24^{\dagger \dagger \dagger}$ & $138.3 \pm 9.2^{\dagger \dagger \dagger}$ & $622 \pm 57^{\dagger \dagger \dagger}$ & $61.8 \pm 9.1^{\dagger \dagger \dagger}$ & $<10^{\dagger \dagger \dagger}$ \\
BDL $1 \mathrm{~g} / \mathrm{kg} /$ day & $366 \pm 46^{\dagger \dagger \dagger}$ & $80 \pm 7^{\$}$ & $155.3 \pm 13.8^{\dagger \dagger \dagger}$ & $771 \pm 69^{\dagger \dagger \$}$ & $68.2 \pm 5.8^{\dagger \dagger \$}$ & $<10^{\dagger \dagger \dagger}$ \\
BDL 4 g/kg/day & $486 \pm 67^{\dagger \dagger \dagger}$ & $100 \pm 13^{\dagger}$ & $183.4 \pm 18.2^{\dagger \dagger \dagger}$ & $730 \pm 79^{\dagger \dagger \dagger}$ & $58.9 \pm 7.7^{\dagger \dagger \dagger}$ & $<10^{\dagger \dagger \dagger}$ \\
\hline
\end{tabular}

Data are expressed as mean \pm SEM.

ALT, alanine aminotransferase; AP, alkaline phosphatase; AST, aspartate aminotransferase; BDL, bile-duct ligation; GGT, $\gamma$ glutamyl transpeptidase.

$* P<0.001$, significantly different from nontreated sham-operated controls.

$\dagger P<0.05$.

$\dagger \uparrow P<0.001$, significantly different from corresponding treated sham-operated controls group.

$\S P<0.05$, significantly different from nontreated BDL

Arterial ammonia significantly increased in nontreated BDL rats $(177.3 \pm 30.8 \mu \mathrm{M}$ versus sham: $66.5 \pm 18.2 \mu \mathrm{M}$, $P<0.01)$. All doses of AST-120 significantly decreased ammonia in BDL rats to similar levels found in respective sham-operated controls: $0.1 \mathrm{~g} / \mathrm{kg} / \mathrm{day}: 121.9 \pm 13.8 \mu \mathrm{M}$ versus $81.1 \pm 8.9 \mu \mathrm{M}, P>0.05 ; 1 \mathrm{~g} / \mathrm{kg} / \mathrm{day}$ : $80.9 \pm 30.0 \mu \mathrm{M}$ versus $72.2 \pm 6.3 \mu \mathrm{M}, P>0.05 ; 4 \mathrm{~g} / \mathrm{kg} /$ day: $48.8 \pm 19.6 \mu \mathrm{M}$ versus $53.8 \pm 16.8 \mu \mathrm{M}, P>0.05$. Furthermore, ammonia levels were significantly lower in treated BDL compared with nontreated BDL rats (Fig. 3A). Ammonia levels significantly correlated with dose of AST-120 (Spearman $r=-0.6603 ; P=0.0006)$ (Fig. 3B). 

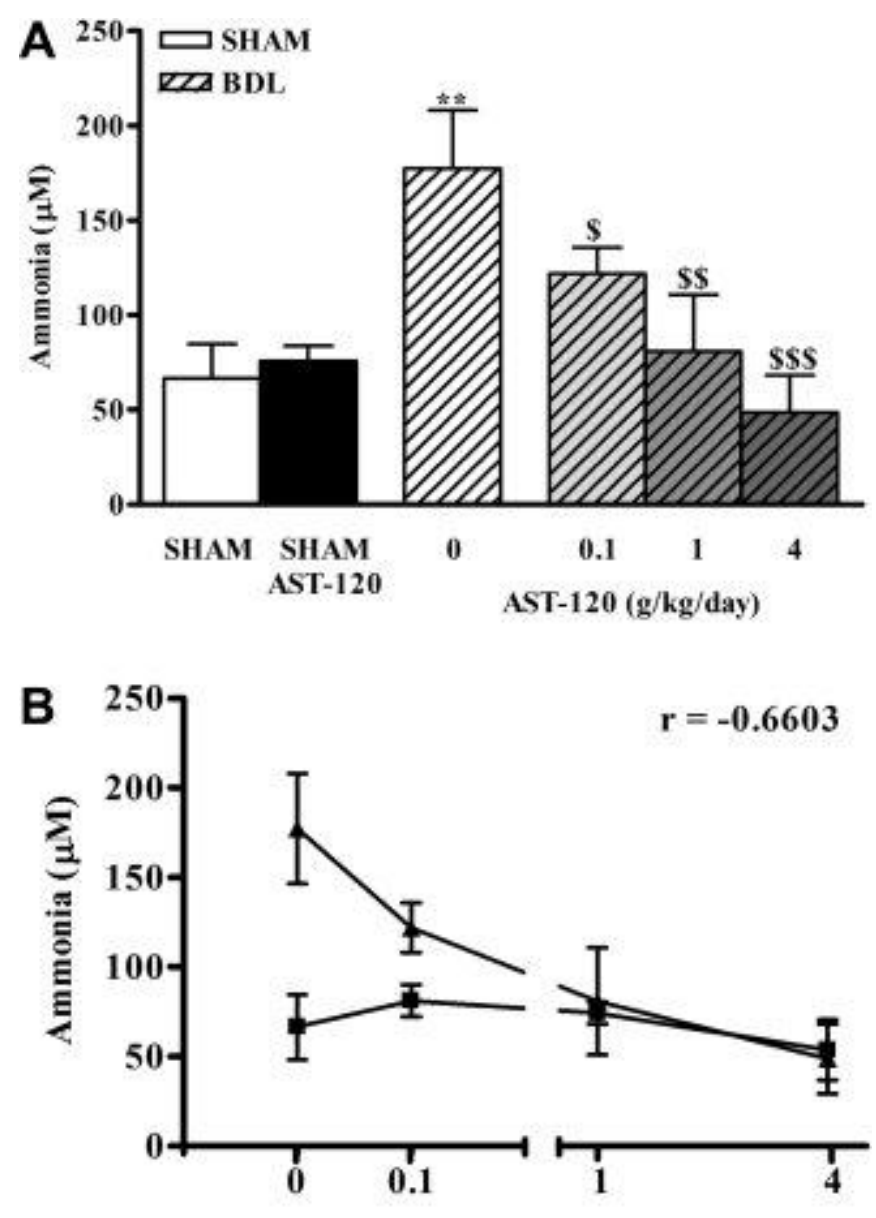

$\operatorname{AST}-120(\mathrm{~g} / \mathrm{kg} / \mathrm{day})$

Figure 3. (A) Arterial ammonia concentrations after treatment with AST-120, 0.1, 1, and $4 \mathrm{~g} / \mathrm{kg} / \mathrm{day}$ for 6 weeks in bile duct-ligated (BDL) and sham-operated rats. Because no significant differences were found between the three groups of AST-120-treated sham-operated rats, only the mean value for these groups is presented to simplify the figure. Data are expressed as mean \pm SEM. $* * P<0.01$, significantly different from nontreated sham-operated controls; ${ }^{\$} P<0.05,{ }^{\$} P<0.01,{ }^{\$ \$} P<0.001$, significantly different from nontreated BDL. (B) Correlation between ammonia levels and AST-120 dose (Spearman $r=-0.6603 ; P$

$=0.0006, \cdot=$ sham,$\wedge=\mathrm{BDL})$.

\section{ROS.}

Arterial ROS levels significantly increased in nontreated BDL compared with sham-operated rats $(P<0.01)$. After AST-120 treatment, ROS levels remained significantly higher compared with respective sham-operated controls, and no significant change was observed between nontreated and AST-120-treated BDL rats (Fig. 4). 


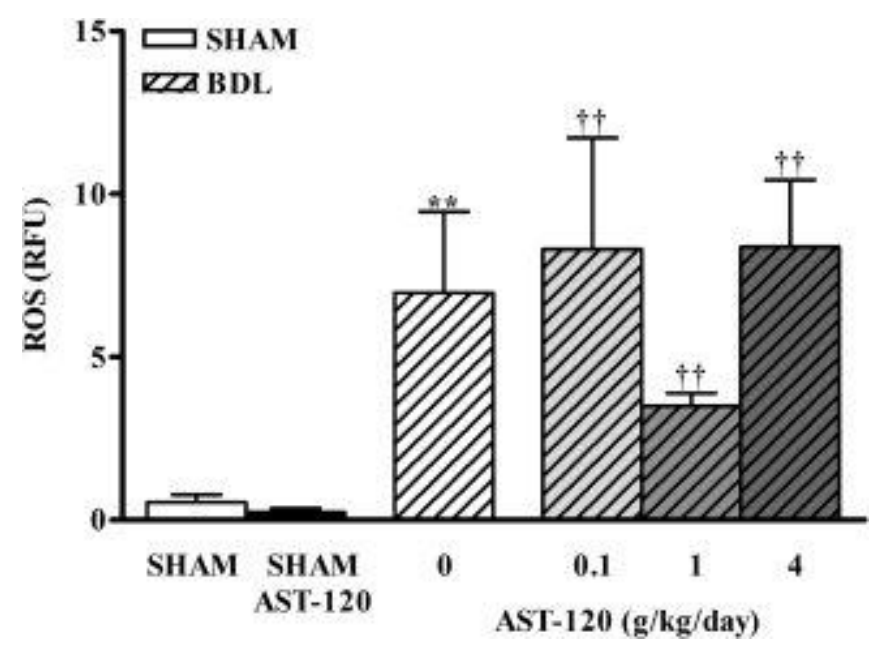

Figure 4. Arterial ROS concentrations after treatment with AST-120, 0.1, 1, and $4 \mathrm{~g} / \mathrm{kg} / \mathrm{day}$ for 6 weeks in bile duct-ligated (BDL) and sham-operated rats. Because no significant differences were found between the three groups of AST-120-treated sham-operated rats, only the mean value for these groups is presented to simplify the figure. Data are expressed as mean \pm SEM. $* * P<0.01$, significantly different from nontreated sham-operated controls; $\dagger \dagger P<0.01$, significantly different from corresponding treated sham-operated control group.

\section{Brain Edema.}

Brain water content in the frontal cortex was found to be significantly increased in nontreated BDL rats (79.39\% $\pm 0.22 \%$ versus nontreated sham: $78.60 \% \pm 0.19 \%, P<0.05)$ and in $0.1 \mathrm{~g} / \mathrm{kg} /$ day AST-120-treated BDL rats $(79.53 \% \pm 0.30 \%$ versus respectively treated sham: $78.76 \% \pm 0.15 \%, P<0.05)$. AST -120 , at 1 and $4 \mathrm{~g} / \mathrm{kg} / \mathrm{day}$, lowered brain water content in the frontal cortex to values similar to that of their respective sham-operated controls, although no difference was observed when compared with nontreated BDL (Fig. 5A). 

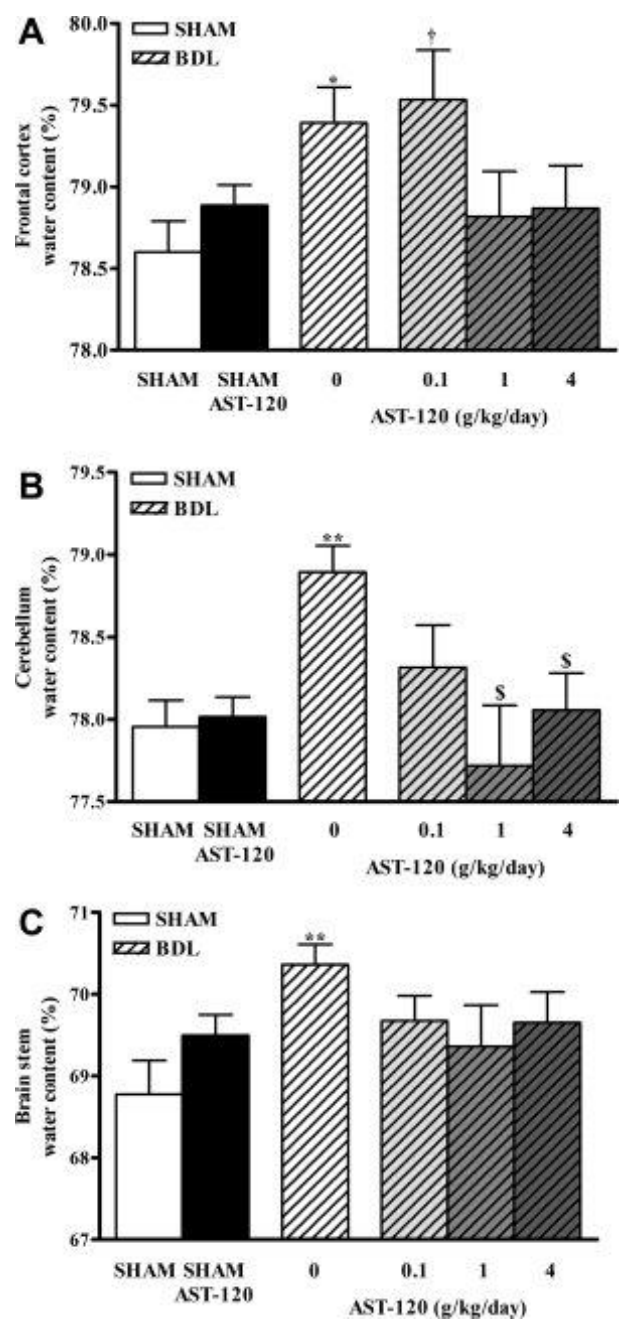

Figure 5. (A) Frontal cortex, (B) cerebellum, and (C) brainstem water content after treatment with AST-120, 0.1, 1, and $4 \mathrm{~g} / \mathrm{kg} /$ day for 6 weeks in bile duct-ligated (BDL) and sham-operated rats. Because no significant differences were found between the three groups of AST-120treated sham-operated rats, only the mean value for these groups is presented to simplify the figure. Data are expressed as mean \pm SEM. $* P<0.05, * * P<0.01$, significantly different from nontreated sham-operated controls; $\uparrow P<0.05$, significantly different from corresponding treated sham-operated controls group; ${ }^{\$} P<0.05$, significantly different from nontreated BDL.

Brain water content significantly increased in nontreated BDL rats in cerebellum $(78.89 \% \pm 0.16 \%$ versus nontreated sham: $77.96 \% \pm 0.16 \%, P<0.01)$ and brainstem $(69.50 \% \pm 0.25 \%$ versus nontreated sham: $68.78 \% \pm$ $0.41 \%, P<0.01)$. All doses of AST-120 lowered brain water content in cerebellum and brain stem to values similar to their respective sham-operated controls. In cerebellum, no difference was found between AST-120 at $0.1 \mathrm{~g} / \mathrm{kg} /$ day treated BDL rats versus nontreated BDL rats, whereas AST-120 at 1 and $4 \mathrm{~g} / \mathrm{kg} /$ day presented a significant reduction versus nontreated BDL $(P<0.05)$. In brainstem, no difference was observed between AST$120-$ treated and nontreated BDL rats (Fig. 5B, C).

\section{Effect of AST-120 Administered as Short-Term Treatment.}

Because AST-120 administered preventively for 6 weeks lowered arterial ammonia levels and normalized brain water content, we investigated the effect of AST-120 when administered as short-term treatment. One gram per 
kilogram per day AST-120 was investigated as the treatment dose, because it was the lowest dosage that reduced both ammonia and brain edema after 6 weeks of treatment.

The AST-120 (1 g/kg/day) administered for 2 weeks (weeks 4-6) and 3 days (days 39-42) significantly reduced arterial ammonia levels compared with nontreated BDL rats (nontreated BDL: 267\% versus AST-120-treated BDL: $108 \%$ [2 weeks] and 105\% [3 days] relative to respective sham-operated controls). Brain water content decreased in all three regions (frontal cortex, cerebellum, and brain stem) to similar levels as sham-operated controls (Fig. 6A).
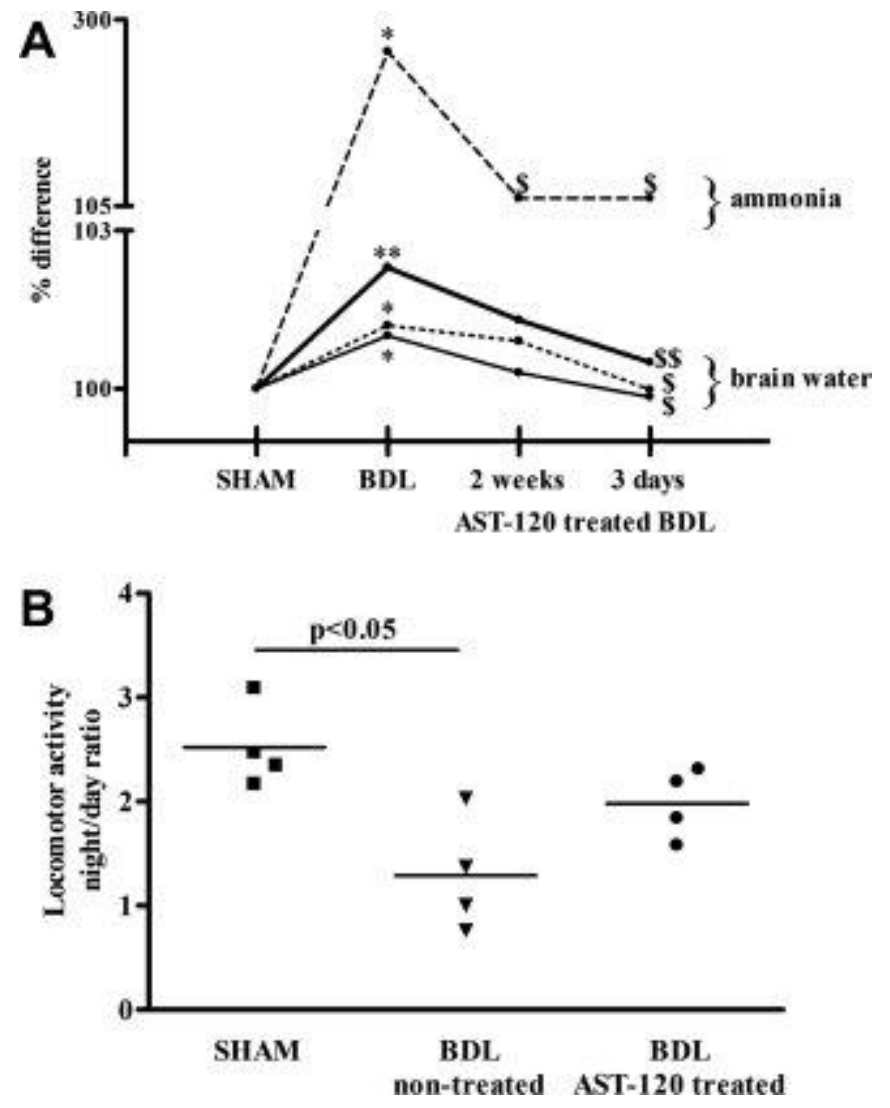

Figure 6. (A) Arterial ammonia and frontal cortex, cerebellum, and brainstem water content percent change after treatment with AST-120, $1 \mathrm{~g} / \mathrm{kg} /$ day for 2 weeks and 3 days in bile ductligated (BDL) and sham-operated rats. Data are expressed as percent change relative to shamoperated controls. $* P<0.05$, $* * P<0.01$, significantly different from nontreated sham-operated controls; ${ }^{\$} P<0.05$, significantly different from nontreated BDL; ${ }^{\$} P<0.01$, significantly different from nontreated BDL (- - Ammonia; - Frontal cortex water content; ….. Cerebellum water content; - Brainstem water content). (B) Locomotor activity after treatment with AST-120, 1 $\mathrm{g} / \mathrm{kg} /$ day for 2 weeks in bile duct-ligated (BDL) and sham-operated rats. Data are expressed as night/day ratio of cumulative distance traveled recorded over 12 hours active period (night) and 12 hours inactive period (day).

\section{Locomotor Activity.}

Locomotor activity in BDL rats was reduced compared with sham-operated controls but normalized after AST120 treatment ( $1 \mathrm{~g} / \mathrm{kg} /$ day for 2 weeks) (Fig. 6B). 


\section{Adsorption of Blood Ammonia by AST-120.}

To determine AST-120's capability to remove ammonia from the blood, both nontreated and AST-120-treated BDL rats were infused (intravenously) with ammonium acetate. In nontreated BDL rats, ammonium acetate infusions $(55 \mu \mathrm{mol} / \mathrm{kg} / \mathrm{minute})$ led to a rapid increase in blood ammonia and consequently a fast deterioration in neurological status (80\% progressed to precoma during the 3-hour observation period). Whereas AST-120 significantly attenuated an increase in blood ammonia, and only 14\% of AST-120-treated BDL rats progressed to precoma (Fig. 7).

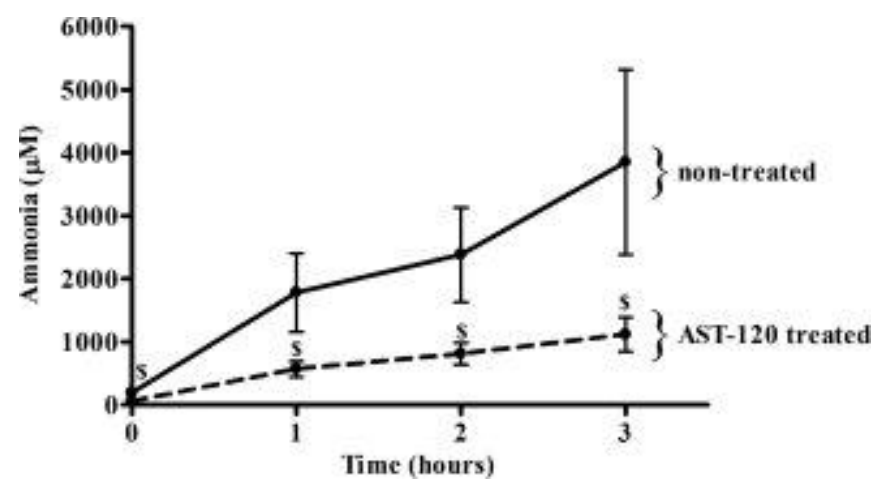

Figure 7. Time course of arterial ammonia concentrations after ammonium acetate intravenous infusions in nontreated and AST-120, $1 \mathrm{~g} / \mathrm{kg} /$ day for 2 weeks treated bile duct-ligated (BDL) rats. Data are expressed as mean \pm SEM. ${ }^{\$} P<0.05$, significantly different from nontreated BDL. (nontreated BDL rats; - - - AST-120 treated BDL rats).

\section{DISCUSSION}

Results of the current study demonstrate that AST-120 treatment (both as a preventive and short-term therapy) lowers arterial ammonia levels, attenuates brain edema, and improves locomotor activity. No significant effect on circulating ROS was noted. These results demonstrate the important role of ammonia in the pathogenesis of brain edema. Furthermore, it suggests that systemic oxidative stress independently does not lead to brain edema and is not induced by hyperammonemia. We also demonstrate that AST-120 has the capability of lowering ammonia by adsorbing both gut-derived and blood-derived ammonia.

Before testing AST-120 in vivo, we tested its capacity to adsorb ammonia in vitro. AST-120 significantly adsorbed ammonia from $100-\mu \mathrm{M}$ and $1 \mathrm{mM}$ solutions, which represent the range reported in humans with $\mathrm{HE}$, ${ }^{11}$ as well as in animal models of HE. ${ }^{28}$ In vitro, ammonia adsorption occurred rapidly and efficiently, providing a good rationale to test AST-120 as an ammonia-lowering treatment in vivo.

The different treatment periods were chosen accordingly to different pathological aspects in the time course of HE. In patients with cirrhosis, a preventive treatment would be useful for reducing the onset of minimal HE or the number of episodes of overt HE, whereas short-term treatment would be useful in treating episodes of HE (see nomenclature of $\mathrm{HE}^{34}$ ). In BDL rats, 4 weeks after surgery, blood ammonia levels are increased, but brain edema is not present ${ }^{35}$; brain edema is observed only 5 weeks after BDL. ${ }^{10}$ We began AST-120 treatment immediately after surgery (for 6 weeks) to investigate the preventive effect of a long-term treatment on ammonia and brain edema; 4 weeks after surgery ( 2 weeks' treatment) to investigate the capacity of lowering ammonia levels before the apparition of brain edema; and 39 days after surgery ( 3 days' treatment) to investigate the shortterm treatment capacity to lower ammonia and normalize brain water. Our data suggest that AST-120 can be used to prevent an increase in blood ammonia as well as treat hyperammonemia. 
In BDL rats, AST-120 treatment was well tolerated; no adverse effects were observed; weight curves and daily protein intake were not altered. AST-120 treatment had no effect on liver necrosis and cholestasis markers, however, ammonia levels significantly decreased in a dose-response manner.

Ammonia, as a gas $\left(\mathrm{NH}_{3}\right)$ and ion $\left(\mathrm{NH}_{4}^{+}\right)$, can easily diffuse and be transported across plasma membranes. ${ }^{4}$ To better understand the mechanism of action of AST-120, we investigated its capability to remove blood-derived ammonia and found that AST-120 significantly prevented an increase in blood ammonia after intravenous ammonium acetate infusion. This suggests that ammonia diffuses not only from the gut to the portal system, but also from systemic circulation to the gut; and AST-120 in the gut acts as an ammonia sink, significantly clearing blood-derived ammonia.

To date, only acute, high ammonia concentrations have proven to induce oxidative stress both in vitro $(5 \mathrm{mM}$ applied to the astrocytes in culture $\left.{ }^{16}\right)$ and in vivo $\left(12 \mathrm{mmol} / \mathrm{kg}\right.$ administered intraperitoneally in $\left.\mathrm{rat}^{17}\right)$. Interestingly, in the current study, lowering ammonia levels did not lead to a reduction in ROS, suggesting that oxidative stress persists in the absence of hyperammonemia.

Previous studies demonstrated that AST-120 attenuated oxidative stress in rats with chronic kidney disease, by adsorbing uremic intestinal toxins. ${ }^{26}$ The current data suggest that systemic oxidative stress in BDL rats is not directly related to gut-derived toxins such as ammonia and is likely related to a result of the primary liver injury. ${ }^{36}$

Reduction of ammonia levels after AST-120 treatment leads to a normalization of brain water content. These data sustain the important role of ammonia in the pathogenesis of brain edema in chronic liver failure but do not exclude that oxidative stress could exacerbate ammonia effect on HE. ${ }^{18}$ The fact that AST-120 at $0.1 \mathrm{~g} / \mathrm{kg} / \mathrm{day}$ decreased water content only in cerebellum and brainstem and not in frontal cortex, despite a significant decrease in ammonia levels, sustains previous findings that white matter is more amenable to therapy than gray matter. ${ }^{37}$

The protective effect of AST-120 on brain edema is the result of ammonia adsorption. This study confirms that ammonia remains an important factor in the pathogenesis of HE; however, the relation between ammonia, oxidative stress, and brain edema in chronic liver failure requires further investigation.

Traditional HE treatments such as nonabsorbable disaccharides and protein restriction are limited because of the high frequency of adverse reactions. ${ }^{38}$ New treatments are required, and gut-targeted ammonia therapies are warranted. The main mechanisms for eradicating ammonia include sterilizing the gut (antibiotic therapy), acidifying and flushing the gut (lactulose/lactilol), or selectively binding local toxins (AST-120). Thus far, some promising new therapies are being advanced in the clinic: OCR-002 (ornithine-phenylacetate) reduces systemic ammonia levels and brain edema in cirrhotic rats, ${ }^{10}$ and rifaximin (nonabsorbable antibiotic) maintains remission and reduces risk of hospitalization from HE. ${ }^{39}$ In the current study, AST-120 significantly lowered ammonia and protected against the development of brain edema in rats with chronic liver failure. In this context, further studies in humans are warranted to evaluate the utility of AST-120 as a gut ammonia-sequestering agent and its potential benefit in the management of HE.

\section{Acknowledgements}

The authors thank Dr. Jean Côté from the Department of Pathology, CHUM, Université de Montréal for interpreting the liver histology slides.

\section{REFERENCES}

1. Bajaj JS, Hafeezullah M, Franco J, Varma RR, Hoffmann RG, Knox JF, et al. Inhibitory control test for the diagnosis of minimal hepatic encephalopathy. Gastroenterology. 2008;135:1591-1600. 
2. Cooper AJ, Plum F. Biochemistry and physiology of brain ammonia. Physiol Rev. 1987;67:440-519.

3. Felipo V, Butterworth RF. Neurobiology of ammonia. Prog Neurobiol. 2002;67:259-279.

4. Bosoi CR, Rose CF. Identifying the direct effects of ammonia on the brain. Metab Brain Dis. 2009;24:95-102.

5. Córdoba J, Mínguez B. Hepatic encephalopathy. Semin. Liver Dis. 2008;28:70-80.

6. Blei AT. Brain edema in acute liver failure. Crit Care Clin. 2008;24:99-114.

7. Häussinger D. Low grade cerebral edema and the pathogenesis of hepatic encephalopathy in cirrhosis. Hepatology. 2006;43:1187-1190.

8. Rovira A, Mínguez B, Aymerich FX, Jacas C, Huerga E, Córdoba J, et al. Decreased white matter lesion volume and improved cognitive function after liver transplantation. Hepatology. 2007;46:1485-1490.

9. Shah NJ, Neeb H, Kircheis G, Engels P, Häussinger D, Zilles K. Quantitative cerebral water content mapping in hepatic encephalopathy. Neuroimage. 2008;41:706-717.

10. Davies NA, Wright G, Ytrebø LM, Stadlbauer V, Fuskevåg O, Zwingmann C, et al. L-ornithine and phenylacetate synergistically produce sustained reduction in ammonia and brain water in cirrhotic rats. Hepatology. 2009;50:155-164.

11. Kundra A, Jain A, Banga A, Bajaj G, Kar P. Evaluation of plasma ammonia levels in patients with acute liver failure and chronic liver disease and its correlation with the severity of hepatic encephalopathy and clinical features of raised intracranial tension. Clin Biochem. 2005;38:696-699.

12. Ong JP, Aggarwal A, Krieger D, Easley KA, Karafa MT, Lente FV, et al. Correlation between ammonia levels and the severity of hepatic encephalopathy. Am J Med. 2003;114:188-193.

13. Nicolao F, Efrati C, Masini A, Merli M, Attili AF, Riggio O. Role of determination of partial pressure of ammonia in cirrhotic patients with and without hepatic encephalopathy. J. Hepatol. 2003;38:441-446.

14. Weissenborn K, Ahl B, Fischer-Wasels D, van den Hoff J, Hecker H, Burchert W, et al. Correlations between magnetic resonance spectroscopy alterations and cerebral ammonia and glucose metabolism in cirrhotic patients with and without hepatic encephalopathy. Gut. 2007;56:1736-1742.

15. Seyan AS, Hughes RD, Shawcross DL. Changing face of hepatic encephalopathy: role of inflammation and oxidative stress. World J. Gastroenterol. 2010;16:3347-3357.

16. Norenberg MD, Jayakumar AR, Rama Rao KV, Panickar KS. New concepts in the mechanism of ammonia-induced astrocyte swelling. Metab Brain Dis. 2007;22:219-234.

17. Kosenko E, Venediktova N, Kaminsky Y, Montoliu C, Felipo V. Sources of oxygen radicals in brain in acute ammonia intoxication in vivo. Brain Res. 2003;981:193-200.

18. Häussinger D, Görg B. Interaction of oxidative stress, astrocyte swelling and cerebral ammonia toxicity. Curr Opin Clin Nutr Metab Care. 2010;13:87-92.

19. Ljubuncic P, Tanne Z, Bomzon A. Evidence of a systemic phenomenon for oxidative stress in cholestatic liver disease. Gut. 2000;47:710-716.

20. Ramachandran A, Prabhu R, Thomas S, Reddy JB, Pulimood A, Balasubramanian KA. Intestinal mucosal alterations in experimental cirrhosis in the rat: role of oxygen free radicals. Hepatology. 2002;35:622-629.

21. Kmieć Z. Cooperation of liver cells in health and disease. Adv Anat Embryol Cell Biol. 2001;161:III-XIII, 1-151.

22. Pun PBL, Lu J, Moochhala S. Involvement of ROS in BBB dysfunction. Free Radic Res. 2009;43:348-364.

23. Norenberg MD, Rao KVR, Jayakumar AR. Mechanisms of ammonia-induced astrocyte swelling. Metab Brain Dis. 2005;20:303-318.

24. Shen B, Pardi DS, Bennett AE, Queener E, Kammer P, Hammel JP, et al. The efficacy and tolerability of AST-120 (spherical carbon adsorbent) in active pouchitis. Am. J. Gastroenterol. 2009;104:1468-1474.

25. Hiraishi M. The effect of oral adsorbent on surgically induced hepatic failure. Jpn J Surg. 1987;17:517-527.

26. Owada S, Maeba T, Sugano Y, Hirayama A, Ueda A, Nagase S, et al. Spherical carbon adsorbent (AST-120) protects deterioration of renal function in chronic kidney disease rats through inhibition of reactive oxygen species production from mitochondria and reduction of serum lipid peroxidation. Nephron Exp. Nephrol. 2010;115:101-111.

27. Pockros P, Hassanein T, Vierling J, Heuman D, Hillebrand D, Chojkier M, et al. Phase 2, Multicenter, Randomized Study of Ast-120 (spherical Carbon Adsorbent) Vs. Lactulose in the Treatment of Low-Grade Hepatic Encephalopathy (HE). J Hepatol. 2009;50:105.

28. Rose C, Butterworth RF, Zayed J, Normandin L, Todd K, Michalak A, et al. Manganese deposition in basal ganglia structures results from both portal-systemic shunting and liver dysfunction. Gastroenterology. 1999;117:640-644.

29. Córdoba J, Gottstein J, Blei AT. Chronic hyponatremia exacerbates ammonia-induced brain edema in rats after portacaval anastomosis. J. Hepatol. 1998;29:589-594.

30. Setsukinai K, Urano Y, Kakinuma K, Majima HJ, Nagano T. Development of novel fluorescence probes that can reliably detect reactive oxygen species and distinguish specific species. J. Biol. Chem. 2003;278:3170-3175. 
31. Marmarou A, Poll W, Shulman K, Bhagavan H. A simple gravimetric technique for measurement of cerebral edema. J Neurosurg. 1978;49:530-537.

32. Butterworth RF, Lalonde R, Power C, Baker GB, Gamrani H, Ahboucha S. Dehydroepiandrosterone sulphate improves cholestasis-associated fatigue in bile duct ligated rats. Neurogastroenterol. Motil. 2009;21:1319-1325.

33. Palm K, Luthman K, Ros J, Gråsjö J, Artursson P. Effect of Molecular Charge on Intestinal Epithelial Drug Transport: pH-Dependent Transport of Cationic Drugs. Journal of Pharmacology and Experimental Therapeutics. 1999;291:435 443.

34. Ferenci P, Lockwood A, Mullen K, Tarter R, Weissenborn K, Blei AT. Hepatic encephalopathy-definition, nomenclature, diagnosis, and quantification: final report of the working party at the 11th World Congresses of Gastroenterology, Vienna, 1998. Hepatology. 2002;35:716-721.

35. Wright G, Davies NA, Shawcross DL, Hodges SJ, Zwingmann C, Brooks HF, et al. Endotoxemia produces coma and brain swelling in bile duct ligated rats. Hepatology. 2007;45:1517-1526.

36. Bruck R, Shirin H, Aeed H, Matas Z, Hochman A, Pines M, et al. Prevention of hepatic cirrhosis in rats by hydroxyl radical scavengers. J. Hepatol. 2001;35:457-464.

37. Sen S, Rose C, Ytrebø LM, Davies NA, Nedredal GI, Drevland SS, et al. Effect of albumin dialysis on intracranial pressure increase in pigs with acute liver failure: a randomized study. Crit. Care Med. 2006;34:158-164.

38. Phongsamran PV, Kim JW, Cupo Abbott J, Rosenblatt A. Pharmacotherapy for hepatic encephalopathy. Drugs. 2010;70:1131-1148.

39. Bass NM, Mullen KD, Sanyal A, Poordad F, Neff G, Leevy CB, et al. Rifaximin treatment in hepatic encephalopathy. N. Engl. J. Med. 2010;362:1071-1081. 